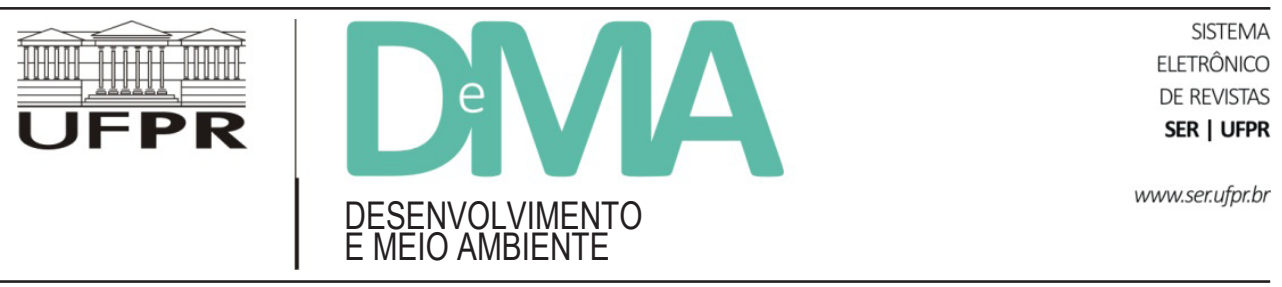

\title{
Barômetro da Sustentabilidade aplicado a assentamentos rurais do leste do Estado do Pará, Brasil
}

\section{Barometer of Sustainability Applied to Rural Settlements from East of State of Pará, Brazil}

\author{
Veríssimo César Sousa SILVA ${ }^{1,2 *}$, Ima Célia Guimarães VIEIRA ${ }^{1,2}$ \\ ${ }^{1}$ Museu Paraense Emílio Goeldi (MPEG), Belém, PA, Brasil. \\ ${ }^{2}$ Programa de Pós-Graduação em Ciências Ambientais (PPCGA), Universidade Federal do Pará (UFPA), Belém, PA, Brasil. \\ *E-mail de contato: verissimo_cesar@yahoo.com.br
}

Artigo recebido em 21 de fevereiro de 2015, versão final aceita em 20 de abril de 2016.

RESUMO

A sustentabilidade dos projetos de assentamentos rurais na Amazônia tem sido questionada no que diz respeito aos impactos ambientais e à precariedade socioeconômica das populações assentadas. Nos últimos anos, várias metodologias de avaliação da sustentabilidade desses assentamentos têm sido propostas, porém os desafios ainda são enormes, no sentido de incorporar uma visão multidimensional na avaliação da qualidade dos assentamentos. O presente trabalho tem por objetivo, então, analisar o nível de sustentabilidade dos assentamentos do Pará, Brasil, por meio da ferramenta Barômetro da Sustentabilidade (BS). Foram selecionados quatro temas (social, econômico-produtivo, organizacional e ambiental) e 28 indicadores, extraídos de um diagnóstico socioambiental efetuado pelo Instituto Nacional de Colonização e Reforma Agrária -INCRA - e foram comparadas duas categorias de assentamentos: Projetos de Assentamentos Convencionais (PAC) e Projetos de Assentamentos Diferenciados (PAD). A pesquisa mostrou que as duas categorias de assentamentos rurais não têm proporcionado uma boa qualidade de vida às famílias, considerando a precariedade de serviços básicos ofertada aos assentados. Por outro lado, os projetos de assentamentos diferenciados, embora estejam na mesma situação de sustentabilidadedos convencionais (Potencialmente Insustentável, segundo o BS), apresentam-se com maior potencial de sustentabilidade econômica e ecológica.

Palavras-chave: desenvolvimento sustentável; assentamentos rurais; indicadores de sustentabilidade.

ABSTRACT: The sustainability of rural settlements projects in Amazon has been questioned with regard to environmental impacts and socio-economic precariousness of rural populations. In recent years, several methods of assessing the sustainability of these settlements have been proposed, but the challenges are still enormous in order to incorporate a multidimensional view in assessing the quality of these settlements. This study aims to analyze the level of sustainability of rural settlements of Pará state, Brazil through the Sustainability Barometer (BS). Four themes were selected (social, economic- productive, organizational and environmental) and 28 indicators drawn from a social and environmental assessment made by the National Institute of Colonization 
and Agrarian Reform - INCRA. Two categories of settlements were compared: Conventional Projects (PAC) and Environmental Differentiated Projects (PAD). Both categories of rural settlements were demonstrated not to provide good quality of life to families considering the precariousness of basic services offered to rural settlers. On the other hand, both categories of settlement are in the same situation in terms of sustainability (Potentially Unsustainable - according to BS), the PAD model presents greater potential for economic and ecological sustainability.

Keywords: sustainable development; rural settlements; sustainability indicators.

\section{Introdução}

Os assentamentos rurais se tornaram um dos principais elementos do mundorural na Amazônia Legal, representando quase um terço das terras usadas e quase $74 \%$ dos estabelecimentos rurais (Le Tourneau \& Bursztein, 2010). Até 2015, havia 3.589 projetos de assentamentos rurais na região, ocupando uma área de 41,8 milhões de hectares (IPAM, 2016). Sabe-se que esses assentamentos são fundamentais para a distribuição de terras e representam uma tentativa de valorização do potencial de sustentabilidade da agricultura familiar (Coca, 2013). OEstado do Pará concentra o maior número de famílias assentadas do país, com mais de $30 \%$ de sua área coberta por assentamentos e historicamente tem sido considerado um dos Estados que mais desmatam (Calandino et al, 2012).

A partir de uma abordagem de desenvolvimento territorial sustentável para o II Plano Nacional de Reforma Agrária do país (Girardi \& Fernandes 2008), o Instituto Nacional de Colonização e Reforma Agrária (INCRA) implantou quatro modalidades de assentamentos rurais de reforma agrária: o Projeto de Assentamento (PA); o Projeto Agroextrativista (PAE); o Projeto de Assentamento Agroflorestal (PAF); e o Projeto de Desenvolvimento Sustentável (PDS), sendo que o PAE, o PAF e o PDS são considerados projetos de assentamento ambientalmente diferenciados, destinados, principalmente, às comunidades tra- dicionais que baseiam sua exploração no extrativismo. Esses últimos são territorializados apenas na Amazônia.

Em geral, os principais problemas dos assentamentos na região amazônica estão relacionados a disputas de apropriação de seus recursos naturais e à precariedade de acesso a crédito, insumos e assistência técnica para promover a produção sustentável, além da falta de regularização ambiental e fundiária que impossibilita a boa governança (Vieira et al., 2014).Apesar da importância da questão, ainda são raros os exemplos de planejamento e acompanhamento de assentamentos na Amazônia que aproveitem o potencial de técnicas e metodologia para tentar entender a sustentabilidade nos assentamentos (Batistella \& Brondizio, 2004).

Esta pesquisa, de caráter descritivo-analítica, objetivou analisar o nível de sustentabilidade de duas modalidades de assentamentos localizados no leste do Pará: os Projetos de Assentamentos Ambientalmente Diferenciados (PAD), representados pela modalidade de Projeto de Assentamento Agroextrativista (PAE), e os Projetos de Assentamentos Convencionais (PAC). Para isso, utilizou-se o Barômetro da Sustentabilidade (BS), uma ferramenta de mensuração da sustentabilidade que tem sido usada no Brasil para avaliar a sustentabilidade em escalas nacional, regional e local (Kronemberger et al., 2008). 


\subsection{Medidas de sustentabilidade em assentamentos}

A noção de sustentabilidade, ou desenvolvimento sustentável, em termos agrícolas e/ou agrários, só aparece quando se vincula o debate sobre a crise ambiental ao espaço rural. Para Altieri (1992), uma proposta de desenvolvimento agrícola sustentável deve levar em consideração os níveis de pobreza rural e a degradação do meio ambiente. Para esse autor, a verdadeira sustentabilidade será obtida quando os pequenos produtores incrementarem seu acesso à terra, aos recursos e a uma tecnologia apropriada para manejá-los adequadamente e se organizarem para assegurar o controle dos recursos e o acesso aos mercados.

Os assentamentos rurais de reforma agrária reúnem em torno de si uma estrutura social agrária com base na unidade familiar, trabalho agrícola associativo epreocupação ecológico-ambiental. Porém, medir a sustentabilidade desses assentamentos é uma tarefa complexa, pois o conceito de sustentabilidade abrange diversas questões na determinação do perfil da agricultura familiar e suas especificidades locais (Guerra, 2002).

Inicialmente os assentamentos eram avaliados quase que exclusivamente pelo desempenho econômico, medido pela renda agrícola (Silva, 2001). Sparovek (2003) tenta inserir uma visão multidimensional na busca da avaliação da qualidade dos assentamentos, utilizando uma metodologia que estabeleceu índices temáticos e incorporou a opinião de agricultores assentados, das organizações dos agricultores assentados e de representantes do governo.

Um sistema de monitoramento do desenvolvimento sustentável dos assentamentos de reforma agrária foi apresentado por Fernandes et al. (2007), os quaisusaram as dimensões social, econômico-produtiva, ambiental e organizacional. Sua construção passou pela seleção dos indicadores e pela construção de índices de desenvolvimento sustentável para os assentamentos. Com esse sistema, esses autores identificaram os principais problemas dos assentamentos do Brasil como sendo os de infraestrutura, serviços, produção e renda e desmatamento.

Na Amazônia, Guerra (2002) utilizou 21 indicadores (sociais, econômicos, ambientais e político-institucionais) em Projeto de Desenvolvimento Sustentável no Acre e listou "treze mandamentos" para um projeto ideal de reforma agrária, que vão desde o cronograma para a implantação do projeto até a elaboração de um programa de educação ambiental e de vigilância, além da fiscalização e do acompanhamento do assentamento, mesmo após a sua emancipação.

Em todos esses casos, a análise da sustentabilidade em assentamentos foi feita a partir da identificação dos temas, do estabelecimento dos indicadores e da definição dos limites desses indicadores.

\subsection{Barômetro da Sustentabilidade}

O Índice de Bem-Estar das Nações, chamado também de Barômetro da Sustentabilidade - BS, foi concebido por R. Prescott-Allen em 1997, sob o patrocínio da IUCN (International Union for Conservation of Nature) e do IRDC (International Research Development Center). Foi o primeiro sistema de indicadores internacionais a promover uma visão equilibrada entre aspectos humanos e ecossistêmicos (Marchand \& Le Tourneu, 2014). O Barômetro é dividido em dois componentes: o "bem-estar das sociedades" (que agrupa as dimen- 
sões sociais, econômicas e políticas) e o "bem-estar dos ecossistemas" (Prescott-Allen, 1999).

O BS, por ser flexível e subjetivo, abre espaço para adaptar ou criar uma estrutura mais adequada ao objetivo do usuário. Tanto a escolha dos indicadores a serem utilizadas no BS quanto a forma como serão organizados (em temas, dimensões e eixos de bem-estar) dependem dos objetivos do trabalho, das especificidades da situação em análise, da disponibilidade de informações e do modo como os autores do estudo entendem e interpretam o conceito de sustentabilidade (Kronemberger et al., 2004).

É um sistema de indicadores relativamente simples, que aborda temas mais ou menos universais, além de ser inovador quanto à incorporação de outros, como a cultura (Marchand \& Le Tourneau, 2014). A escala de desempenho é montada dentro de um intervalo que vai de zero a cem. Esse intervalo apresenta cinco subdivisões de classes: Insustentável, Potencialmente Insustentável, Intermediária, Potencialmente Sustentável e Sustentável, nas quais os intervalos dessas subdivisões são definidos pelo usuário do Barômetro e escolhidos conforme critério dos pesquisadores. O valor obtido para cada indicador é então transposto para essa escala do barômetro.

\section{Materiais e métodos}

\subsection{Obtenção dos dados e seleção dos assentamentos}

Os dados utilizados nessa pesquisa foram cedidos oficialmente ao Museu Paraense Emilio Goeldi em 2011 pelo INCRA-SR01, localizado em Belém. São informações que constituem parte integrante do "Diagnóstico socioeconômico e ambiental" (PQRA) efetuado nos Projetos de Assentamentos (PAs) contemplados com a política de Assistência Técnica e Extensão Rural (ATER), que gerencia os Assentamentos Rurais localizados no leste do Pará. Os questionários para o diagnóstico do INCRA foram aplicados em 39 assentamentos no ano de 2010. Ressalte-se que até dezembro de 2015 não houve outro diagnóstico dessa natureza nos assentamentos do Pará.

No presente estudo, a seleção dos assentamentos foi realizada aleatoriamente entre aqueles que tinham pelo menos $5 \%$ das famílias entrevistadas pelo INCRA. As características dos assentamentos selecionados podem ser observadas nas Tabelas 1 e 2 .

\subsection{Aplicação do Barômetro da Sustentabilidade}

\subsubsection{Dimensões, temas e indicadores de sustentabilidade}

Foram consideradas quatro dimensões para análise: social, econômico-produtiva, organizacionale ambiental, como forma de aglutinar os temas e indicadores no BS. Os indicadores escolhidos para compor o BS foram extraídos do questionário "Diagnóstico socioeconômico e ambiental" do INCRA. Assim, foram escolhidos 28 indicadores referentes às quatro dimensões estudadas (Tabelas 3 a 6). Os parâmetros foram definidos com base nas orientações normativas nacionais, regionais e municipais e em consulta à literatura especializada.

O BS foi aplicado separadamente para cada modalidade, PAC (Projeto de Assentamento Convencional) e PAD (Projeto de Assentamento Ambientalmente Diferenciado), agrupando-se os dados de todos os assentamentos em cada modali- 
TABELA 1 - Relação dos Projetos de Assentamentos Convencionais (PAC) e Ambientalmente Diferenciados (PAD) do Pará selecionados para este estudo.

\begin{tabular}{|c|c|c|c|c|c|c|c|}
\hline Nome & Modalidade & $\begin{array}{l}\text { Data de } \\
\text { criação }\end{array}$ & Município & Área (ha) & $\mathrm{N}^{\circ}$ famílias & $\begin{array}{c}\mathrm{N}^{\circ} \text { famílias } \\
\text { entrevistadas }\end{array}$ & $\%$ \\
\hline Arapua Simeira & PAC & 24/12/1996 & $\begin{array}{l}\text { Capitão Poço/ Nova } \\
\text { Esperança do Piriá }\end{array}$ & $74.452,00$ & 53 & 4 & 7,5 \\
\hline Três Irmãos & PAC & $15 / 12 / 2001$ & Aurora do Pará & $3.453,00$ & 99 & 8 & 8,08 \\
\hline Olho D’Água II & PAC & $28 / 11 / 2002$ & Moju & $8.082,00$ & 350 & 27 & 7,7 \\
\hline Taperassu & PAC & $23 / 10 / 2003$ & São Domingos do Capim & $4.196,00$ & 175 & 15 & 8,6 \\
\hline Novo Jauara & PAC & $06 / 09 / 2006$ & Aurora do Pará & $1.509,62$ & 390 & 25 & 6,4 \\
\hline Pequiarana Mirim & PAD & $19 / 10 / 2006$ & Abaetetuba & 580,7501 & 160 & 15 & 9,3 \\
\hline Ilha Paquetá & PAD & $27 / 06 / 2008$ & $\begin{array}{c}\text { São Sebastião da Boa } \\
\text { Vista }\end{array}$ & 813,86 & 116 & 9 & 7,8 \\
\hline Ilha Ponta Alegre & PAD & $26 / 11 / 2008$ & Curralinho & 26,7 & 40 & 3 & 7,5 \\
\hline Ilha São Raimundo & PAD & $26 / 11 / 2008$ & Curralinho & $2.968,53$ & 150 & 12 & 8 \\
\hline
\end{tabular}

TABELA 2 - Dimensão social: temas, indicadores e parâmetros para a construção das escalas de desempenho do BS de assentamentos do leste do Pará.

\begin{tabular}{|c|c|c|c|}
\hline$\stackrel{\Xi}{\ddot{E}}$ & Indicadores & Referências e Fontes & Parâmetros \\
\hline \multirow{2}{*}{ : } & $\begin{array}{l}\text { Estado geral } \\
\text { da escola }\end{array}$ & $\begin{array}{l}\text { Brasil, LEI FEDERAL } \\
9.394 / 96\end{array}$ & \multirow{6}{*}{$\begin{array}{l}\text { Meta: } 100 \% \text { das famílias entrevistadas assentadas que consideraram opção } \\
\text { "boa" e/ou "ótima" como respostas do PQRA. }\end{array}$} \\
\hline & Acesso à escola & $\begin{array}{l}\text { Brasil, LEI FEDERAL } \\
9.394 / 96\end{array}$ & \\
\hline \multirow{4}{*}{ 串 } & $\begin{array}{l}\text { Acesso ao hospital e posto } \\
\text { de saúde }\end{array}$ & $\begin{array}{l}\text { Brasil, CONSTITUIÇÃO } \\
\text { FEDERAL de 1988, } \\
\text { ARTIGO } 196 .\end{array}$ & \\
\hline & Água pra consumo & $\begin{array}{l}\text { Carneiro et al., (2008). } \\
\text { BRASIL, LEI FEDERAL } \\
11.445 / 07\end{array}$ & \\
\hline & Consulta médica & $\begin{array}{l}\text { BRASIL, Lei } 8.080 \text {, de } 19 \text { de } \\
\text { Setembro de } 1990 .\end{array}$ & \\
\hline & Agente de Saúde & $\begin{array}{l}\text { BRASIL, LEI FEDERAL } \\
11.350 / 06\end{array}$ & \\
\hline \multirow{2}{*}{ 恶 } & Tipo de moradia & \multirow{2}{*}{$\begin{array}{l}\text { BRASIL, LEI FEDERAL } \\
11.445 / 07\end{array}$} & $\begin{array}{l}\text { Meta: } 100 \% \text { das famílias entrevistadas assentadas que consideraram } \\
\text { opção "Alvenaria/tijolo - com reboco", "Alvenaria/tijolo - sem reboco" e } \\
\text { "madeira" como respostas do PQRA. }\end{array}$ \\
\hline & Energia Elétrica & & $\begin{array}{l}\text { Meta: } 100 \% \text { das famílias entrevistadas assentadas que consideraram opção } \\
\text { "Disponibilidade de energia elétrica o ano todo em condições adequada ao } \\
\text { conforto da família" como respostas do PQRA. }\end{array}$ \\
\hline \multirow{2}{*}{ 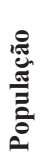 } & $\begin{array}{l}\text { Pessoas abaixo da linha da } \\
\text { pobreza }\end{array}$ & $\begin{array}{l}\text { MINISTÉRIO PÚBLICO } \\
\text { SIIS/PA (2010) }\end{array}$ & Meta: $100 \%$ das famílias com renda familiar acima da linha da pobreza \\
\hline & $\begin{array}{l}\text { Família atendida com } \\
\text { bolsa Família/escola. }\end{array}$ & $\operatorname{MDS}(2013)$ & Meta: $100 \%$ das famílias entrevistadasatendidas com bolsa família/escola \\
\hline
\end{tabular}

FONTE: Elaborado pelos autores. 
dade. Assim, foi obtido apenas um índice no eixo de Bem-Estar Humano (social, econômico e organizacional) e um índice do Bem-Estar Ambiental (ecológico) para cada modalidade.

A dimensão social é formada por quatro temas (educação, saúde, moradia e educação), subdivididos em dez (10) indicadores (estado geral da escola, acesso à escola, acesso a hospital e posto de saúde, água para consumo, consulta médica, agente de saúde, tipo de moradia, energia elétrica, pessoas abaixo da linha da pobreza e famílias atendidas por bolsa família).
A dimensão econômica é formada por apenas um tema (renda e comércio) com três indicadores (renda da produtividade, comercialização da produção vegetal no lote e comercialização da produção animal no lote) (Tabela 3).

A dimensão organizacionalé formada por um tema (parcerias institucionais) e composta por seis indicadores (instituições de assistência técnica, associação/cooperativa, comércio local, prefeitura municipal, Instituto Nacional Colonização e Reforma Agrária - INCRA e no de famílias com acesso ao PRONAF).

TABELA 3 - Dimensão econômica: temas, indicadores e parâmetros para a construção das escalas de desempenho do BS de assentamentos do leste do Pará.

\begin{tabular}{|c|c|c|c|}
\hline 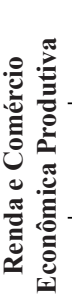 & $\begin{array}{l}\text { Comercialização da } \\
\text { produção vegetal no lote } \\
\text { Comercialização da } \\
\text { produção animal no lote }\end{array}$ & BRASIL, DECRETO 7.358 & $\begin{array}{l}\text { Meta: } 100 \% \text { das famílias entrevistadas assentadas que consideraram } \\
\text { opção "comercialização direta para o consumidor" e/ou "cooperativa" } \\
\text { como respostas do PQRA. }\end{array}$ \\
\hline
\end{tabular}

FONTE: Elaborado pelos autores.

TABELA 4 - Dimensão organizacional: temas, indicadores e parâmetros para a construção das escalas de desempenho do BS de assentamentos do leste do Pará.

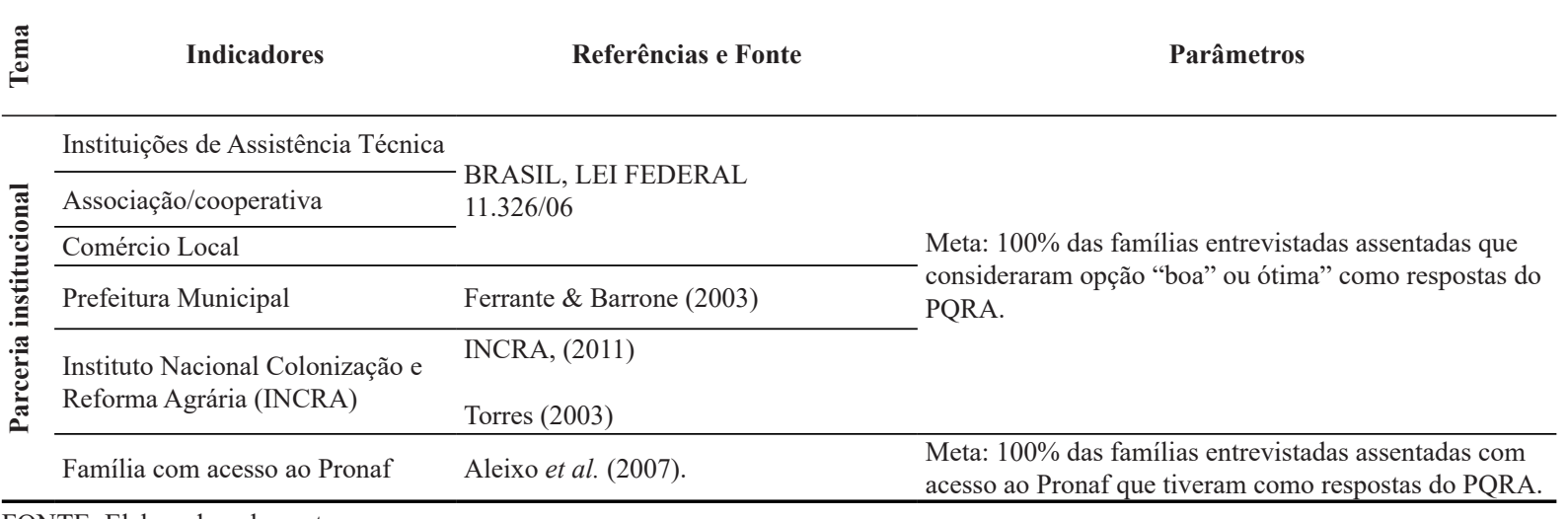

FONTE: Elaborado pelos autores. 
A dimensão ambiental é composta por dois temas (água e terra), constituídos de nove indicadores (tratamento de água, destino do dejeto humano, uso de agrotóxico, deposição de lixo, queimada, recuperação de área degradada, consórcio, pousio e área desmatada).

\subsubsection{Construção da escala de desempenho}

As escalas de desempenho (ED) dos indicadores foram construídas de acordo com Kronemberger et al. (2008). Os valores limites dos intervalos foram escolhidos com base em revisão de literatura, trabalhos de relevância em outros assentamentos, dados oficiais de instituições federais, estaduais e municipais, para reduzir a subjetividade da escolha desses limites (Tabela 6).

Os limites dos intervalos de sustentabilidade das escalas de desempenho das variáveis têm correspondência com a Escala do Barômetro. Após a elaboração da escala de desempenho, foi feita a transposição do valor real do indicador para a escala do BS (EDB), por meio de interpolação linear simples. A Figura 1 ilustra a transposição de escalas e a relação entre os valores da escala de desempenho DAx e EBx, ou seja, a escala EDA (Escala de Desempenho do Assentamento) crescente ou decrescente.

TABELA 5 - Dimensão ambiental: temas, indicadores e parâmetros para a construção das escalas de desempenho do BS de assentamentos do leste do Pará.

\begin{tabular}{cc}
\hline Indicadores & Parâmetros a serem construídos para definir os limites da escala de \\
desempenho
\end{tabular}

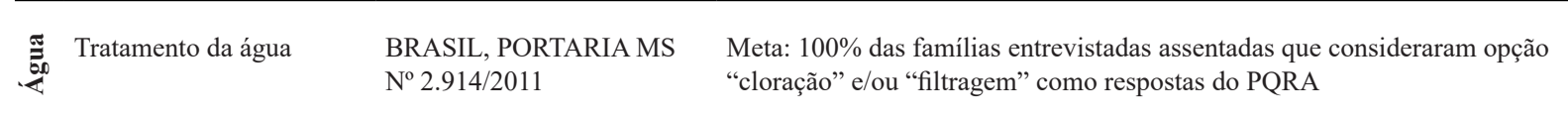

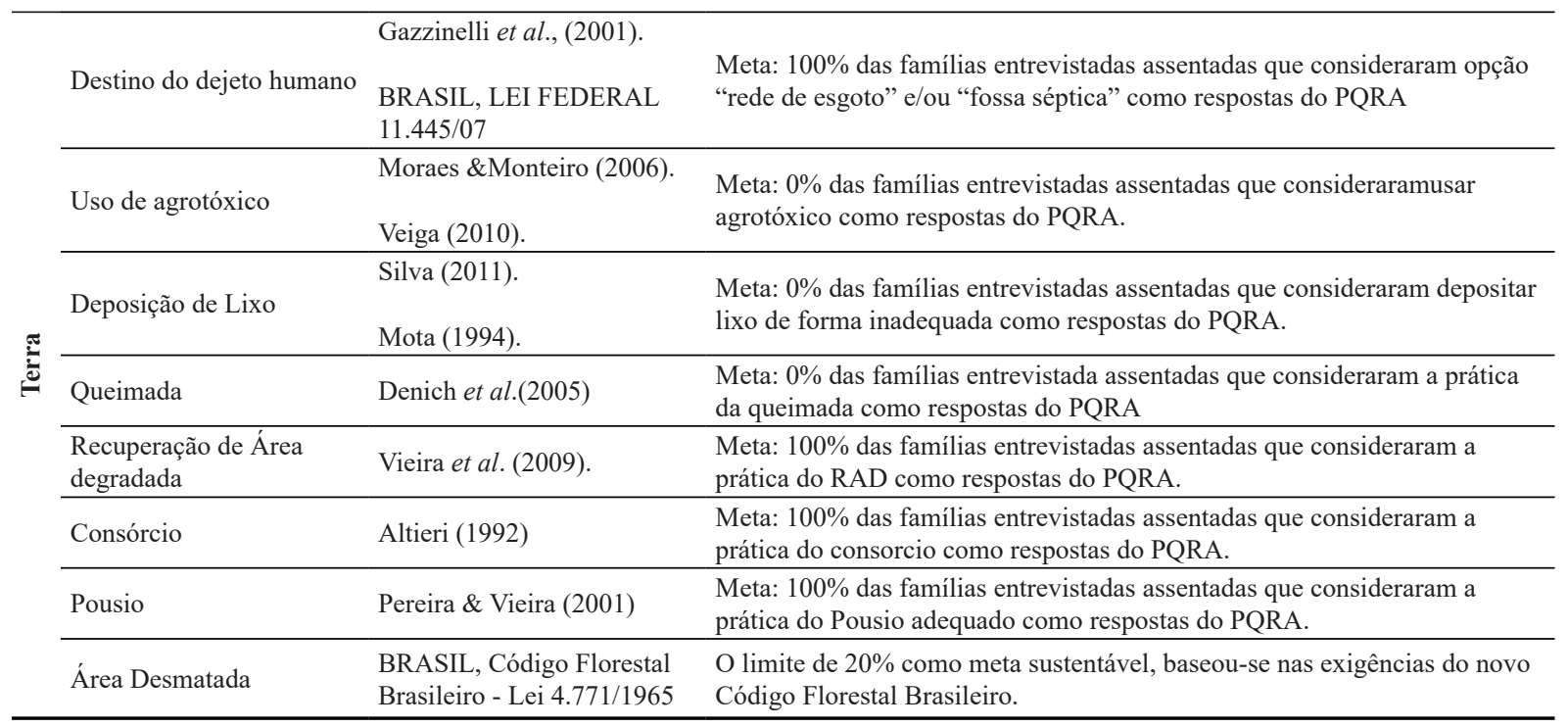

FONTE: Elaborado pelos autores. 


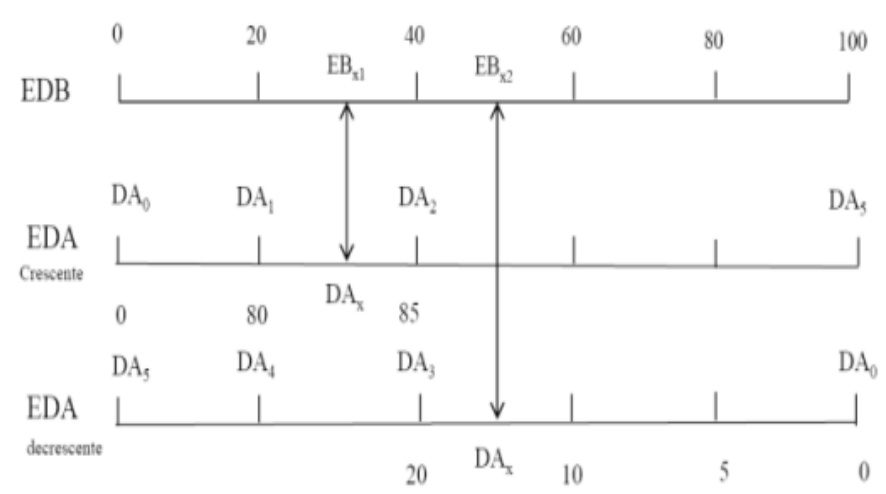

Cálculo do grau de EDAX na escala EBS:

$\mathrm{EBx}=\mathrm{EBa}+\underline{(\mathrm{DAx}-\mathrm{DAa})(\mathrm{EBa}-\mathrm{EBp})}$

(DAa - DAp)

$\mathrm{EBx}=$ valor na Escala do Barômetro

DAx $=$ valor na Escala de Desempenho do Assentamento

$\mathrm{x}=$ valor da variável $\mathrm{X}$ nas diferentes escalas

$\mathrm{a}=$ limite anterior do intervalo que contém $\mathrm{X}$

$\mathrm{a}=$ limite posterior do intervalo que contém

$\mathrm{p}=$ limite posterior do intervalo que contém $\mathrm{X}$.

FIGURA 1 - Fórmula de ajuste da escala dos indicadores dos assentamentos para a escala do Barômetro Fonte: Adaptado de Kronemberger et al. (2004).

A Tabela 6 mostra a escala de desempenho dos indicadores usados neste estudo. Essa atribui, a cada indicador avaliado, um grau (nível) de sustentabilidade, o qual varia do insustentável (0) ao sustentável (100). A posição vai depender do valor real que cada indicador possui.

\subsection{Os índices do $B S$}

Os resultados em termos de sustentabilidade (aplicada à escala de desempenho) das variáveis individuais são reunidos por temas. Os índices desses temas são agrupados por dimensões, os das dimensões por eixos e os resultados das médias desses grandes eixos são expressos em um diagrama bidimensional, com os dois principais índices criados: o índice de bem-estar humano (HWI) e o índice de bem-estar ecológico (EWI), que compreende a média não ponderada das dimensões envolvidas e que possibilita analisar as interações entre eles. $\mathrm{O}$ terceiro índice e o mais importante desta metodologia é o índice de bem-estar (WI). Trata-se de um gráfico no qual os índices de bem-estar humano e de bem-estar ecológico são representados graficamente com seus respectivos eixos. A interseção entre os eixos $\mathrm{Y}$ e $\mathrm{X}$ fornece uma medida da sustentabilidade ou insustentabilidade do sistema. 
TABELA 6 - Ajustes das Escalas de Desempenho dos Indicadores de Desenvolvimento Sustentável (IDS) das quatro dimensões analisadas emrelação à escala do Barômetro da Sustentabilidade para assentamentos do leste do Pará.

\begin{tabular}{|c|c|c|c|c|c|c|c|}
\hline \multirow{4}{*}{ Indicadores } & \multirow{3}{*}{\multicolumn{2}{|c|}{ Valores Reais }} & \multicolumn{5}{|c|}{ ESCALA DO BARÔMETRO DA SUSTENTABILIDADE } \\
\hline & & & \multicolumn{2}{|r|}{$21-40$} & \multirow{2}{*}{$\begin{array}{c}\text { 41-60 } \\
\text { Interme- } \\
\text { diário }\end{array}$} & \multirow{2}{*}{$\begin{array}{c}61-80 \\
\text { Potencial- } \\
\text { mente } \\
\text { susten-tável } \\
\end{array}$} & \multirow{3}{*}{$\begin{array}{c}\text { 81-100 } \\
\text { Susten- } \\
\text { tável }\end{array}$} \\
\hline & & & $\begin{array}{c}\text { 0-20 } \\
\text { Insus- } \\
\text { tentável }\end{array}$ & $\begin{array}{c}\text { Potencial- } \\
\text { mente insus- } \\
\text { tentável }\end{array}$ & & & \\
\hline & PAC & PAD & \multicolumn{4}{|c|}{ ESCALA DE DESEMPENHO DOS INDICADORES } & \\
\hline Estado geral da escola & 49,5 & 49,2 & \multirow{5}{*}{$>30$} & \multirow{5}{*}{$31-50$} & \multirow{5}{*}{$51-80$} & \multirow{5}{*}{$81-90$} & \multirow{5}{*}{$91-100$} \\
\hline Acesso ao hospital e posto de saúde & 21,1 & 6,2 & & & & & \\
\hline Consulta médica & 24,8 & 15,4 & & & & & \\
\hline Agente de Saúde & 30,3 & 49,2 & & & & & \\
\hline Água para consumo & 29,5 & 1,5 & & & & & \\
\hline Linha da pobreza $(\%)$ & 40,4 & 61,5 & $>50$ & $50-31$ & $30-21$ & $20-10$ & $<10$ \\
\hline Programa Bolsa Família (\%) & 43,3 & 47,9 & $0-20$ & $21-40$ & $41-60$ & $61-80$ & $81-100$ \\
\hline Renda total & 12,8 & 7,7 & \multirow{3}{*}{$>30$} & \multirow{3}{*}{$31-50$} & \multirow{3}{*}{$51-80$} & \multirow{3}{*}{$81-90$} & \multirow{3}{*}{$91-100$} \\
\hline $\begin{array}{l}\text { Comercialização da produção vegetal } \\
\text { no lote }\end{array}$ & 5,5 & 6,2 & & & & & \\
\hline $\begin{array}{l}\text { Comercialização da produção animal no } \\
\text { lote }\end{array}$ & 9 & 9,2 & & & & & \\
\hline Instituições de assistência técnica & 2,8 & 12,3 & \multirow{2}{*}{$>30$} & \multirow{2}{*}{$31-50$} & \multirow{2}{*}{$51-80$} & \multirow{2}{*}{$81-90$} & \multirow{2}{*}{$91-100$} \\
\hline Associação/cooperativa & 19,3 & 33,8 & & & & & \\
\hline Tratamento da água & 57,8 & 70,8 & \multirow{2}{*}{$->30$} & \multirow{2}{*}{$31-50$} & \multirow{2}{*}{$51-80$} & \multirow{2}{*}{$81-90$} & \multirow{2}{*}{$91-100$} \\
\hline Destino do Dejeto Humano & 11 & Zero & & & & & \\
\hline Uso de Agrotóxico & Zero & 1,1 & \multirow{3}{*}{$>71$} & & & & \\
\hline Deposição de Lixo & 4 & 14,1 & & $70-31$ & $30-11$ & $10-6$ & $5-0$ \\
\hline Queimada & 70 & 3 & & & & & \\
\hline Recuperação de área degradada & 3,1 & 18,2 & & & & & \\
\hline Consórcio & 36 & Zero & 30 & $31-50$ & $51-80$ & $81-00$ & 01 \\
\hline Pousio & 44 & 21,4 & & & & & \\
\hline Área Desmatada & zero & 100 & & & & & \\
\hline
\end{tabular}

FONTE: Os autores. 


\section{Resultados e discussão}

\subsection{As dimensões da sustentabilidade dos assentamentos}

A combinação dos 28 indicadores resultou em oito índices, um para cada tema de cada dimensão (Tabela 7).

$\mathrm{Na}$ análise do conjunto dos temas do BS, observa-se que o nível de sustentabilidade do PAD foi melhor na dimensão ambiental, alcançando o nível médio. O PAC, por outro lado, foi melhor avaliado na educação, com posição intermediária.Os aspectos de cada dimensão são discutidos a seguir.

\subsubsection{Dimensão social}

Referente ao conjunto de indicadoressociais (Figura 2),observa-se que o indicador"tipo de moradia" apresentou-se com bons índices para as duas modalidades, podendo ser explicado pelo fato de que a satisfação das famílias assentadas reflete as situações vivenciadas anteriormente em situação de acampamento, bem como o sonho de ter acesso à terra, que inclui, entre outros aspectos, uma moradia de melhor qualidade, acesso à escola, estado geral da escola e agente de saúde para ambas as modalidades.

TABELA7 - Resultados dos índices para cada tema do Barômetro da Sustentabilidade, para as modalidades de assentamento PAC ePAD, localizados no leste do Pará.PAC - Projeto de Assentamentos Convencionais; PAD - Projeto de Assentamento Diferenciado.

\begin{tabular}{lccc}
\hline TEMA & PAC & PAD & Nível de sustentabilidade \\
\hline DIMENSÃo SOCIAL & & 38,5 & PAC - Intermediário \\
Educação & 41,1 & 13,9 & PAD - Potencialmente Insustentável \\
Saúde & 17,5 & 49,5 & Insustentável \\
Moradia & 47,3 & 25,7 & Potencialmente Insustentável \\
População & 22,8 & 2,5
\end{tabular}

DIMENSÃO ECONÔMICA

Renda e comércio
11,7
34,2
PAC - Insustentável

PAD - Potencialmente Insustentável

\section{DIMENSÃO ORGANIZACIONAL}

Parceria institucional

17,1

15,1

Insustentável

\section{DIMENSÃO AMBIENTAL}

Água

51

52,8

Intermediário

Terra

34,0

45,5

PAC - Potencialmente Insustentável PAD - Intermediário

FONTE: Os autores. 
INDICADORES PARA DIMENSÃO SOCIAL

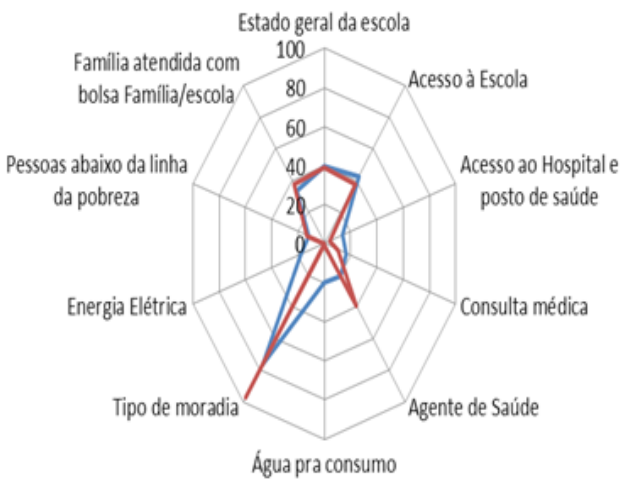

INDICADORES PARA DIMENSÃO ECONÔMICA

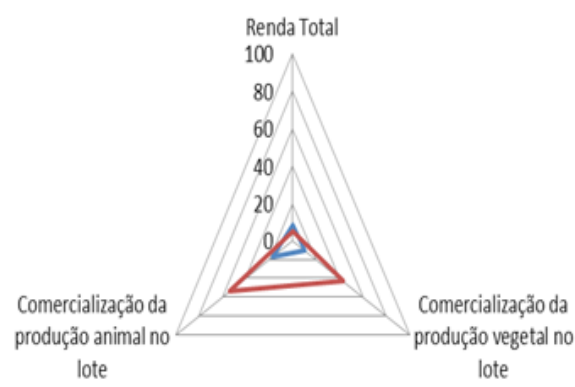

\section{INDICADORES PARA DIMENSÃO INSTITUCIONAL}

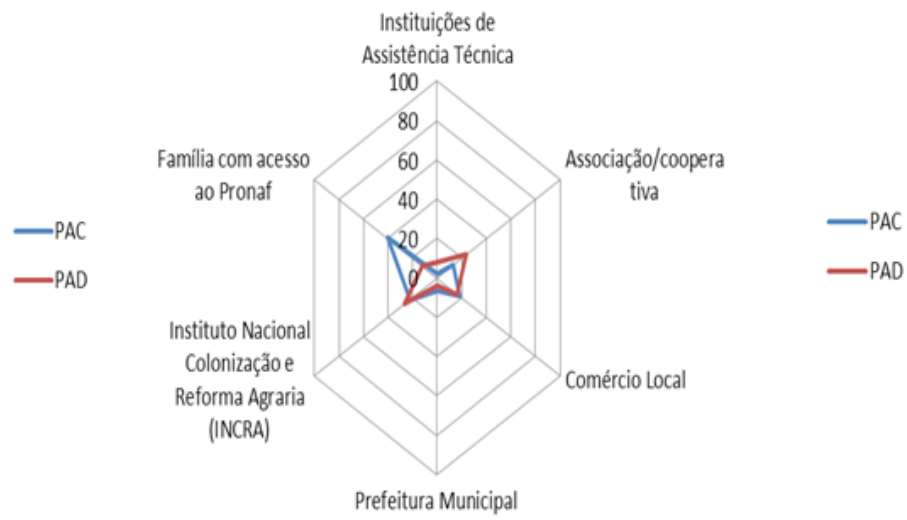

INDICADORES PARA DIMENSÃO AMBIENTAL

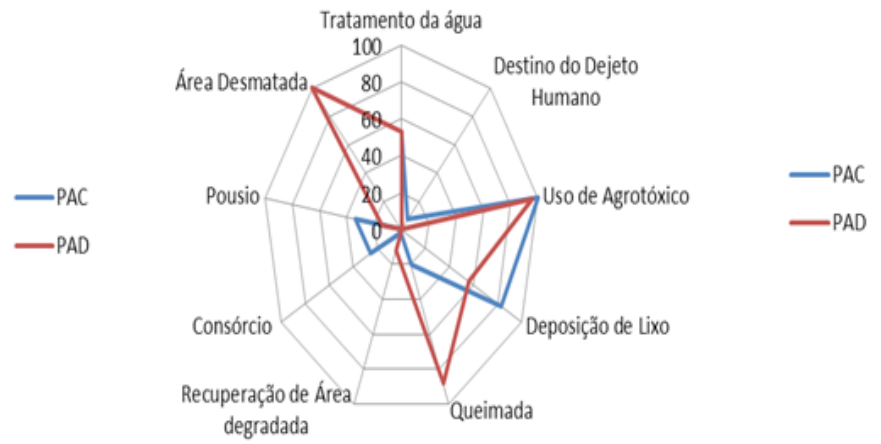

FIGURA 2 - Conjunto de indicadores paraas quatro dimensõesdas duas modalidades de assentamentos do Pará. PAC - Projeto de Assentamentos Convencionais; PAD - Projeto de Assentamento Diferenciado.

FONTE: PQRA/INCRA, 2010.

Diferentemente dos residentes da terra firme, os ribeirinhos vivem em pequenas comunidades em sua maioria à beira dos rios, dos igarapés, dos igapós e dos lagos que compõem o vasto e complexo estuário amazônico. As casas de madeira construídas em palafitas são mais adequadas ao sistema de cheias dos rios e estão dispersas nas chamadas comunidades localizadas próximas aos rios, igarapés, furos e lagos (Noda, 2001).
Os indicadores sistema público de abastecimento de "água para consumo", "energia elétrica" e "acesso ao hospital e posto de saúde" apresentaram os piores índices, pois não há água para consumo de boa qualidade, aoferta de energia elétrica é precária e os meios de transporte existentes não atendem os assentados em suas necessidades de mobilidade, inclusive aos postos de saúde e hospitais. Essa ausência de serviços básicos é pior no PAD. 
Entende-se que a sustentabilidade de um sistema deve considerar haver qualidade de vida, promovendo a satisfação humana. O limitado acesso à água, bem público de direito fundamental, compromete a dinâmica das residências nos trabalhos diários, assim como a garantia de produção de alimentos nos assentamentos. A grandiosidade de oferta de recursos hídricos na Amazônia não constitui, por si só, a possibilidade de atender as necessidades básicas de suas populações. Sob a perspectiva do acesso à água para atendimento de necessidades humanas diárias, pode-se dizer que há escassez de água para consumo na região (Giatti \& Cutolo, 2012) e o Pará tem o pior desempenho dentre os estados amazônicos.

Percebe-se, então, que as políticas efetivadas nos dois tipos de assentamentos analisados não são suficientes para gerar melhoria na qualidade de vida dos assentados. Em geral, os programas sociais em assentamentos são realizados de forma fragmentada, e descontínua, sem um mecanismo eficiente para enfrentar as situações difíceis da vida rural amazônica, que tem um dos mais elevados riscos sociais. É necessário que sejam efetivadas políticas sociais de combate à pobreza e de ampliação de direitos como acesso à moradia, alimentação, saúde, educação e renda, como forma de garantir a melhoria na qualidade de vida dos assentados.

\subsubsection{Dimensão organizacional}

Elevar os indicadores para a posição de Sustentável na escala do Barômetro da Sustentabilidade é garantir que a sustentabilidade institucional/organizacional seja alcançada quando as estruturas e os processos preponderantes têm condições de continuar a desempenhar suas funções em longo prazo (Barreto et al., 2005). Neste estudo, a dimensão organizacional foi trabalhada com o tema parceria, o qual encontrou-se em uma posição Insustentável para as duas modalidades de assentamentos (Tabela 7). O fraco desempenho desse tema mostra a fragilidade institucional associada aos assentamentos na Amazônia.

Levando-se em consideração a Lei da Agricultura Familiar, que estabelece as diretrizes para a formulação da Política Nacional da Agricultura Familiar, o indicador "assistência técnica" apontou uma grande falta de convergência entre a lei, no que diz respeito às ações de Assistência Técnica e Extensão Rural, e a sua execução. A situação é crítica tanto para o PAC quanto para o PAD.

É de fundamental importância, que os assentados tenham uma boa relação com a prefeitura do município onde o assentamento está inserido, para que a gestão municipal possa colaborar para a promoção da qualidade de vida e do bem-estar dessa categoria da população. A ação das prefeituras está centrada no apoio à consolidação de serviços básicos, nem sempre de maneira satisfatória, como o atendimento à saúde e aos serviços educativos do ensino fundamental.

Por isso, foi escolhido o indicador "prefeitura municipal", que se refere à satisfação dos assentados com as ações das Prefeituras. Neste sentido, as duas modalidades tiveram índices baixos. Vê-se, assim, que a ausência do poder municipal agrava o alcance das políticas sociais e de infraestrutura nas duas modalidades de assentamento, tornando deficiente o alcance das políticas sociais para os assentados.

Dessa forma, é importante a atuação da base local para o desenvolvimento sustentável dos projetos de assentamentos, propondo linhas de investimentos (via o Programa Nacional de Fortalecimento da Agricultura Familiar-PRONAF, por exemplo), parcerias e uma série de medidas para a organiza- 
ção local de instituições capazes de acompanhar e suportar a difícil trajetória de consolidação dos assentamentos.

A execução do PRONAF é feita de forma descentralizada e conta com a parceria das organizações dos agricultores familiares, dos governos estaduais e municipais, das organizações governamentais e não governamentais de assistência técnica e extensão rural, das cooperativas de crédito e de produção, dos agentes financeiros, do Serviço Brasileiro de Apoio às Micro e Pequenas Empresas (SEBRAE) e outros.

Observa-se que na modalidade do PAC, apesar de os assentados manterem uma relação Insustentável com as prefeituras onde os projetos estão inseridos, essa mesma modalidade foi considerada com posição intermediáriapara o indicador "famílias com acesso ao PRONAF", enquanto a pior situação foi apresentada pelo PAD, que apontou uma posição Insustentável para esse indicador. No geral, revela-se que o PRONAF não atendeu com efetividade todos os trabalhadores rurais entrevistados nas duas modalidades.

Para Torres (2003), a função do INCRA, legalmente, é apoiar os assentamentos até a sua "emancipação", materializada na transferência da titularidade da terra para os assentados que, doravante, passam a integrar o universo "normal" de agricultores familiares. Como instituição responsável pela gestão dos assentamentos, o INCRA deve desenvolver atividades como parcelamento da terra, projeto de desenvolvimento do assentamento, liberação de créditos, assistência técnica, ou seja, ações que possibilitem o processo produtivo.

Para avaliar a relação dos assentados no trabalho com o INCRA, foi adotado o indicador "Instituto Nacional de Colonização e Reforma Agrária". Com esse indicador, foi obtida uma posição de Potencialmente Insustentável para as duas modalidades, mostrando uma relação ruim entre o órgão e os assentados. Provavelmente as ações de competência da autarquia não estão sendo concretizadas com eficácia e eficiência nos assentamentos de reforma agrária estudados.

Em síntese, a dimensão organizacional medida pelo tema parceria sinalizou uma posição Insustentável para as duas modalidades, não apresentando nenhum indicador com posição confortável (Potencialmente Sustentável ou Sustentável). Famílias com acesso ao PRONAF foi o indicador que se mostrou mais expressivo dentro deste tema, apenas para a modalidade de PAC (Figura 2), o que leva a refletir que a participação ou satisfação dos assentados é mínima.

Os indicadores desse tema, localizados nos pontos críticos do sistema, reforçam a necessidade de melhorar a participação e a organização interna do assentamento. Na perspectiva do desenvolvimento social local, há estudos(Ferrari, 2007) que mostram que há amplo consenso sobre a necessidade da participação ativa dos agricultores familiares nos processos de construção do desenvolvimento local para que sua sustentabilidade sociopolítica seja assegurada.Por outro lado, a viabilidade dos assentamentos não deve ser vista apenas do ponto de vista da produção de alimentos, mas também na formação de novos agentes sociais capazes de garantir a sua reprodução econômica, a sustentabilidade e a participação social nas decisões da comunidade.

\subsubsection{Dimensão econômica}

O tema renda e comércio foi avaliado por meio de três indicadores e apresentou uma posição Insustentável para a modalidade de PAC e Potencialmente Insustentável para o PAD na escala do BS (Tabela 7).Observou-se que, em relação 
à renda total no PAD, mais da metade $(62 \%)$ da renda é advinda da somatória da renda das lavouras, olericultura, fruticultura, extração de madeira, extrativismo, produção animal, processamento e beneficiamento da produção para cada família das duas modalidades, sendo que $84 \%$ é renda oriunda da venda de açaí, enquanto no PAC apenas $36 \%$ do total da renda vem da produção agrícola, com destaque para a produção animal, que contribui com $43 \%$ da renda da produção.

Apesar de haver uma parcela bastante significativa da produção extrativista na composição da renda total no PAD, não existe o processamento desses produtos nos assentamentos e isso mostra que a comercialização é feita in natura. Nos assentamentos convencionais, a composição da renda total é dada de forma mais igualitária entre os segmentos e o que influenciou menos o indicador foi a renda do trabalho fora dos assentamentos. Pode-se observar também que, apesar de o PAC ter uma menor parcela da produção na renda total em relação ao $\mathrm{PAD}$, ele tem uma parte significativa no beneficiamento da produção, ou seja, $55 \%$ do que é produzido nos assentamentos estudados podem ser processados de alguma forma nos assentamentos e essa atividade de processamento pode refletirem um maior índice da renda para o PAC.

Em relação à comercialização da produção, a modalidade do PAC teve pior desempenho nas vendas dos seus produtos que o PAD. Para o indicador "comercialização da produção vegetal", as modalidades de PAC e PAD encontraram-se numa posição de Insustentável e Intermediário, respectivamente. O indicador "comercialização de produção animal" também se encontrou numa posição de Insustentável para as duas modalidades.

Para estes indicadores, entendeu-se que a sustentabilidade está ligada à venda dos produtos nas feiras diretamente para os consumidores ou nas cooperativas, não tendo a participação dos atravessadores. Para a World Fair Trade Organization (WFTO, 2004), tem que haver o entendimento de comércio justo, baseado em diálogo, transparência e respeito, que busca maior equidade no comércio. Ele contribui para o desenvolvimento sustentável, por meio de melhores condições de troca e garantia dos direitos para produtores e trabalhadores marginalizados. Sendo assim, a posição de Insustentável para a modalidade PAC reflete uma dificuldade dos produtores dos Assentamentos Convencionais em relação à comercialização dos seus produtos, considerando que menos de $30 \%$ praticam uma comercialização sustentável nas vendas de produção, tanto vegetal quanto animal.

Apesar de o PAC apresentar maior dependência na sua comercialização para os produtos vegetais e animais com os atravessadores, ele apresenta maior renda em relação ao $\mathrm{PAD}$. Isso pode ser explicado pela diversificação da produção e o processamento desses produtos no interior desses assentamentos, ou seja, a obtenção da renda no PAC ocorre de forma mais equilibrada entre os diversos meios de produção. Assim, dos seis meios (lavoura, olericultura, fruticultura, reflorestamento, extrativismo e produção animal), apenas a olericultura não apresentou produção pelas famílias entrevistadas, enquanto que no PAD apenas três meios de produção foram identificados. Ademais, o processo de beneficiamento dos produtos nos assentamentos do PAC teve uma parcela de significância para o aumento da renda total em relação ao PAD, já que neste último nenhuma das famílias entrevistadas declarou que desenvolve algum tipo de processo de beneficiamento dos produtos (Figura 2).

Em geral, a política de localização dos assentamentos, que prioriza áreas remotas, de titularidade duvidosa e acesso restrito à infraestrutura, constitui um dos principais aspectos que inviabilizam 
economicamente estes projetos (Le Tourneau \& Bursztyn, 2010). Ainda, a falta de planejamento, a desorganização de um cronograma de investimentos e a falta de assistência técnica acabam por prejudicar em muito o desenvolvimento econômico dos produtores assentados.

\subsubsection{Dimensão ambiental}

A dimensão ambiental apresentou uma posição Intermediária para as duas modalidades, com 49,1 para o PAD e 42,1 para o PAC, considerando nove indicadores (Tabela 7).

Nesta dimensão, alguns indicadores foram considerados com desempenhos bons para as duas modalidades, como foi o caso do indicador uso de agrotóxico. As duas modalidades tiveram resultados intermediários (razoável) para o indicador tratamento da água. Os indicadores "área desmatada" e "queimada" também tiveram um bom desempenho para a modalidade de assentamento ambientalmente diferenciado (Figura 2).

O indicador "deposição de lixo" para o PAC teve um expressivo resultado. Os indicadores que tiveram desempenhos ruins para a modalidade de assentamentos convencionais foram: "destino do dejeto humano", "recuperação de áreas degradadas" e "área desmatada". Para o PAD, os indicadores que apresentaram piores desempenhos foram: "consórcio", "recuperação de área degradada", "destino do dejeto humano" e "pousio". Nota-se que os indicadores os quais apresentaram baixo desempenho são mais numerosos em comparação aos indicadores com bons desempenhos, para as duas modalidades. Dos noves indicadores selecionados para o PAC, seis possuem posição de Insustentável e Potencialmente Insustentável e apenas três com melhores posições na escala BS. Para o PAD, quatro indicadores estão em posição ruim (Potencialmente Sustentável e Insustentável), mas cinco estão numa posição confortável (Figura 2).

Para as duas modalidades, constatou-se que as práticas convencionaisde recuperação de áreas degradadas, pousio econsórcio de culturas não são amplamente utilizadas nos assentamentos, provavelmente por falta de orientação técnica.

O sistema de agricultura de corte e queima praticado pelos assentados depende da queima da biomassa acumulada durante a recuperação florestal para aumentar as qualidades nutricionais do solo e preparar a área para o cultivo por meio da cinza (Pereira \& Vieira, 2001), mas, a longo prazo, a prática de queimada pode levar à insustentabilidade da produção agrícola, por causa da enorme perda de nutrientes.

Para o indicador "queimada", observou-se que $78 \%$ das famílias do PAC utilizam a prática da queimada em seus lotes, alcançando 20 pontos na escala do BS, o que justifica a posição de Insustentável, enquanto as queimadas no PAD são menos utilizadas pelas famílias entrevistadas. Nessa última modalidade, apenas 3\% do total das famílias consideraram a utilização da prática, alcançando a posição de Sustentável na escala do BS, com índice de 88 pontos. Certamente, a prática do extrativismo dominante neste tipo de assentamento, que se baseia em coleta de produtos na floresta em pé, sem necessidade de derruba e queima, influenciou fortemente nesse resultado.

O indicador "recuperação de áreas degradadas" (RAD) sinalizou um baixo desempenho para as duas modalidades, levando-o a ocupar uma posição Insustentável. Isso demonstra que aprática de recuperar as áreas degradadas dos lotes é pouco efetuada pelos assentados. O RAD visa restaurar áreas que foram alteradas devido ao uso inadequado dos recursos naturais e inclui atividades voltadas 
para a recuperação de danos ambientais: recuperação e/ou correção de solos, recuperação da mata ciliar, reflorestamento de nascentes e outras áreas de interesse ambiental, recuperação de fontes naturais de água, etc.

O consórcio de culturas agrícolas oportuniza elevação da produtividade e eficiência do aproveitamento do solo, proporciona aumento de segurança aos produtores pela variedade de culturas e também elevação da renda líquida dos plantios, pela maior eficiência no uso da água, do solo, de espaços e diminuição do perigo de prejuízos totais (Almeida et al.,2009). Mesmo com esses benefícios que a prática do "consórcio" oferece, infelizmente, as duas modalidades de assentamentos apresentaram posições de Potencialmente Insustentável e de Insustentável. Uma vegetação de pousio, a capoeira, cresce já a partir do primeiro ano quando a área não é mais capinada. Da antiga vegetação abandonada, retiram-se plantas para a construção de casas, máquinas e instrumentos simples, assim como para a obtenção de energia (Pereira \& Vieira, 2001). Para que o pousio seja sustentável, é necessário que esse período de abandono seja suficiente para regenerar a capacidade produtiva da área. Para o indicador "pousio", o PAC sinalizou uma posição Potencialmente Insustentável e a modalidade de PAD apresentou uma posição de Insustentável. Provavelmente o tempo de pousio tem diminuído muito nos assentamentos, o que compromete o uso da capoeira no sistema de produção agrícola.

Para avaliar a ação do desmatamento nas duas modalidades de assentamento, foi escolhido o indicador "área desmatada", com o qual foram obtidos dados de desmatamento nos assentamentos até 2012. A modalidade de PAC teve um índice de zero, ocupando uma posição de Insustentável na escala do BS. A justificativa para esse desempenho é devido às atividades desenvolvidas pelas famílias, tais como agricultura e exploração madeireira, que têm grande potencial para gerar desmatamento e degradação florestal na região (IPAM, 2016).Nessa modalidade não teve nenhum assentamento que tenha desmatado menos de $20 \%$ da sua reserva legal, como exige o Código Florestal. Já a modalidade de PAD alcançou um índice de 100 (cem) pontos na escala de desempenho, ocupando uma posição de Sustentável. Este excelente desempenho pode estar relacionado à orientação maior voltada à produção florestal neste tipo de assentamento e pouco para a produção agropecuária, atividade que representa uma das maiores causas do desmatamento nos assentamentos da região.

Estudo recente do IPAM (2016) mostra que os assentamentos ambientalmente diferenciados contabilizam apenas 7\% do desmatamento em assentamentos da região entre 2003 e 2014, enquanto os projetos de assentamento convencionais (como os PAs) são os que mais converteram florestas em outros usos da terra na Amazônia, agregando $82 \%$ do desmatamento acumulado dentro dos assentamentos. Neste sentido, a consolidação dos assentamentos ambientalmente diferenciados pode representar avanços na redução do desmatamento dentro dos assentamentos.

\subsection{Representação gráfica do $B S$}

As duas modalidades de assentamentos foram representadas em um único gráfico bidimensional, o qual revela a situação da sustentabilidade desses Projetos de Assentamentos. Embora com ligeira diferença, os dois foram considerados Potencialmente Insustentáveis (Figura 3). 


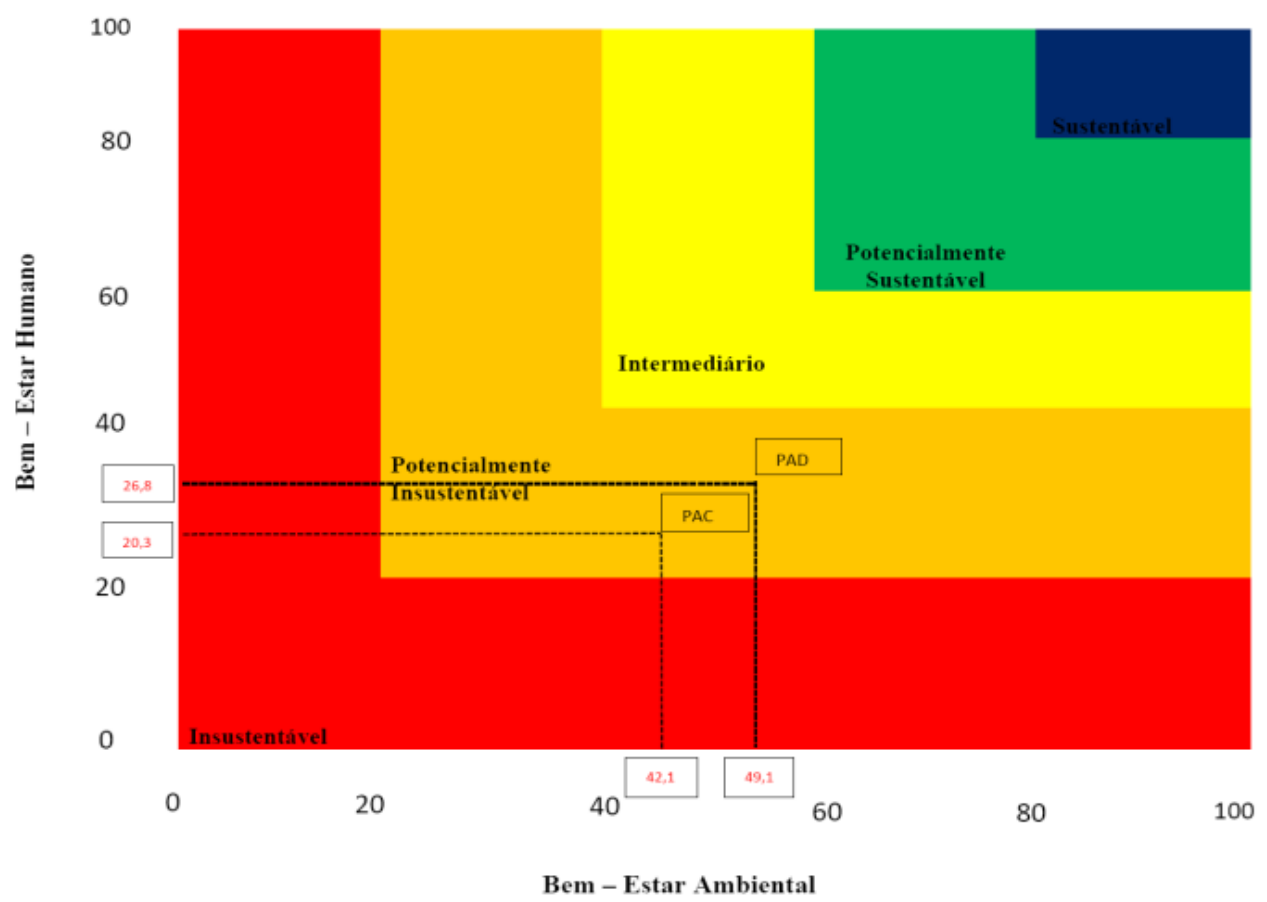

FIGURA 3 - Gráfico bidimensional do Barômetro da Sustentabilidade evidenciando a posição das duas modalidades de assentamento estudadas em relação à sustentabilidade.

FONTE: Elaborado pelos autores, segundo Prescott-Alen (1999).

Assim, nota-se que os Projetos de Assentamentos Diferenciados (PAD) são pouco mais sustentáveis que os Projetos de Assentamentos Convencionais (PAC), mas, apesar de haver essa diferença, as duas modalidades ocupam a mesma posição na escala do Barômetro, com baixa sustentabilidade. Neste estudo, o isolamento geográfico do PAD não se mostrou como fator determinante para indicar a ineficácia da política de reforma agrária nesses assentamentos, comparando-se com o PAC, uma vez que aquela modalidade apresentou melhor desempenho em direção à sustentabilidade em relação a esta última.

A dimensão ambiental apresentou um desempenho mais expressivo em relação a outras dimensões e o maior índice dessa dimensão é na modalidade de projeto ambientalmente diferencia- do. A segunda dimensão melhor ranqueada com bom desempenho foi a social, na qual a modalidade de assentamento convencional teve maior índice em relação ao PAD, porém essa diferença é pequena. Na dimensão econômica, foi identificada uma diferença bastante significativa entre as duas modalidades e essa diferença pode estar relacionada ao processo de produção e comercialização, como foi discutido anteriormente. A dimensão institucional apresentou um baixíssimo desempenho para as duas modalidades, remetendo-se a pensar que é uma dimensão extremamente importante para a sustentabilidade, mas com desempenho sofrível em ambas as modalidades estudadas.

$\mathrm{O}$ acesso a serviços sociais e infraestrutura básica tem um peso importante na qualidade dos assentamentos, interferindo diretamente na perma- 
nência das famílias nos projetos (Bittencourt et al., 1998). Os problemas dos assentamentospodem ser minimizados dependendo das relações dos assentados com os poderes local, regional e federal. $\mathrm{Ou}$ seja, onde existe integração, sensibilidade dos poderes instituídos ou afinidades pessoais e políticas, estas estruturas sãomelhor viabilizadas.

\section{Considerações gerais}

O Barômetro da sustentabilidade permitiu analisar a situação dos assentamentos, podendo assim comparar as duas modalidades e avaliar o nível de interação entre os indicadores, temas e dimensões associados ao desenvolvimento socioambiental de assentamentos de reforma agrária do leste do Pará. Nessa comparação, chama atenção a dimensão econômica, a qualobteve uma diferença significante de 23 pontos na escala BS entre as duas modalidades, com índice maior para o PAD.

Percebe-se, assim, que os assentamentos diferenciados, geralmentelocalizados em áreas remotas, podem ser destinados à reforma agrária, apesar das adversidades impostas pela geografia da região, e que é necessário aproveitar e potencializar a adaptabilidade do ribeirinho a essas condições naturais, garantindo, no mínimo, o acesso à infraestrutura básica de serviços e aos instrumentos de produção necessários ao seu desenvolvimento.

As dimensões organizacionais e sociais não apresentaram diferenças significativas entre as modalidades, porém os resultados obtidos são importantes para refletir sobre os problemas característicos e peculiares dos assentamentos rurais que estão profundamente ligados às propostas do desenvolvimento da agricultura familiar e às políticas destinadas ao seu fortalecimento.
Em particular, é visível a importância da implementação de assentamentos diferenciados, pois a interação homem-natureza dos ribeirinhos e o meio natural que os circunda reflete-se na manutenção da floresta, como bem mostra o indicador área desmatada no PAD, uma vez que os ribeirinhos assentados possuem experiência no uso e na conservação da biodiversidade. Diferente, geralmente, da política que acontece nos projetos convencionais, nos quais ocorre a desapropriação de latifúndio improdutivo geralmente em terras já desmatadas e degradadas, onde as famílias assentadas têm grande potencial para gerar mais desmatamento e degradação ambiental, além de estarem sujeitas à manipulação de madeireiros e fazendeiros que, muitas vezes, são os verdadeiros responsáveis por desmatamentos nos assentamentos.

A pesquisa evidenciou que os dois modelos de assentamentos rurais não têm proporcionado uma boa qualidade de vida às famílias, considerando a precariedade de serviços básicos ofertada aos assentados. Por outro lado, o modelo de assentamentos diferenciados, embora esteja na mesma situação de sustentabilidade dos convencionais, apresenta-se com maior potencial de sustentabilidade econômica e ecológica, e isso é importante para se considerar nas propostas atuais de estabelecer assentamentos sustentáveis (assentamentos verdes). Neste sentido, o estudo do IPAM (2016) faz sugestões de agrupamento de assentamentos considerando estratégias diferenciadas, dependendo da categoria do assentamento e do estágio de consolidação e conservação em que se encontram, e apresenta 13 propostas para promover o desenvolvimento sustentável nos assentamentos da Amazônia. Torna-se importante, assim, a discussão e a implementação dessas estratégias para os assentamentos rurais na Amazônia, onde estejam incluídos a gestão ambiental e o desenho de paisagens sustentáveis. 


\section{Agradecimentos}

Este artigo é parte de uma dissertação de mestrado do Programa de Pós-Graduação em Ciências Ambientais do convênio Universidade Federal do Pará - Museu Emilio Goeldi - Embrapa. Os au-

\section{Referências}

Aleixo, C.E; Cruz, C. E.; Lima, P.V. Importância do PRONAF na infraestrutura, produção agropecuária e geração de renda nos assentamento do Nordeste. In: Anais doXLV SOBER, Londrina, 37(7), 7-16, 2007.

Almeida, M. V. R.; Oliveira, T. S.; Bezerra, A. M. E. Biodiversidade em sistemas agroecológicos no município de Choró, CE, Brasil. Revista Ciência Rural, 39(4), 10801087, 2009.

Altieri, M. A. Biodiversidad, Agroecologia y Manejo de Plagas. Clades: Cetal- Ediciones, 1992. 162 p.

Barreto, R. C. S.; Khan, A. S.; Lima, P. V. P. S. Sustentabilidade dos assentamentos no município de Caucaia-CE. Revista de Economia e Sociologia Rural, 43(2), 225-247, 2005.

Batistella, M.; Brondizio, E. S. Uma estratégia integrada de monitoramento e análise do impacto ambiental de assentamentos rurais na Amazônia. In: Romeiro, A. R. (Org.). Monitoramento e contabilização de impactos ambientais. Campinas: Ed. Unicamp, 2004.p. 74-86.

Bittencourt, G. A.; Castilhos, D. S. B.; Bianchini, V. Principais fatores que afetam o desenvolvimento dos assentamentos de reforma agrária no Brasil, 1998. Disponível em: $<$ http://www.deser.org.br/pub_read.asp?id=67>. Acesso em: dez. 2013.

Brasil. Lei n. 4.771, de 15 de setembro de 1965. Institui o novo Código Florestal Brasileiro. Disponível em: <http:// www.planalto.gov.br/ccivil_03/Leis/L4771.htm>. Acesso em: mar. 2013.

Brasil. Constituição da República Federativa do Brasil, de 5 de outubro de 1988. Disponível em: <http://www. planalto.gov.br/ccivil_03/constituicao/constituicao.htm>. Acesso em: mar. 2013. tores agradecem ao projeto INCT Biodiversidade e Uso da Terra na Amazônia (processo CNPq n. 574008/2008-0) o apoio financeiro para a realização da pesquisa; à CAPES pela concessão de bolsa de mestrado à VCCS e ao CNPq pela bolsa de produtividade de ICGV;

Brasil. Lei n. 8.080, de 19 de setembro de 1990. Dispõe sobre as condições para a promoção, proteção e recuperação da saúde, a organização e o funcionamento dos serviços correspondentes e dá outras providências. Disponível em: $<$ http://www.planalto.gov.br/ccivil_03/leis/18080.htm>. Acesso em: mar. 2013.

Brasil. Lei n. 9.394, de 20 de dezembro de 1996. Estabelece as diretrizes e bases da educação. Disponível em: <portal. mec.gov.br/seed/arquivos/pdf/tvescola/leis/lein9394.pdf $>$. Acesso em: dez. 2011.

Brasil. Lei n. 11.326, de 24 de julho de 2006a. Estabelece as diretrizes para a formulação da Política nacional da Agricultura Familiar e Empreendimentos Rurais Familiares. Disponível em: <http://www.planalto.gov.br/ccivil_03/_Ato2004- 2006/2006/Lei/L11326.htm>. Acesso em: mar. 2013.

Brasil. Lei n. 11350, de 5 de outubro de 2006b. Dispõe sobre as atividades de agente comunitária de saúde e agente de endemias. Disponível em: <http://www.planalto.gov.br/ ccivil_03/_Ato2004-2006/2006/Lei/L11350.htm>. Acesso em: mar. 2013.

Brasil. Lei n. 11.445, de 5 de janeiro de 2007. Estabelece diretrizes nacionais para o saneamento básico. Disponível em: <http://www.planalto.gov.br/ccivil_03/_Ato20072010/2007/Lei/L11445.htm>. Acesso em: mar. 2013.

Brasil. Lei n. 7.358, de 17 de Novembro de 2010. Institui o Sistema Nacional do Comércio Justo e Solidário SCJS, cria sua Comissão Gestora Nacional, e dá outras providências. Disponível em: <http://www.planalto.gov. br/ccivil_03/_ato2007-2010/2010/decreto/d7358.htm>. Acesso em: abr. 2013. 
Brasil. Portaria n. 2.914, de 12 de dezembro de 2011. Estabelece os procedimentos e responsabilidades relativos ao controle e vigilância da qualidade da água para consumo humano e seu padrão de potabilidade, e dá outras providências. Disponível em: <http://dtr2001.saude.gov. $\mathrm{br} / \mathrm{sas} /$ PORTARIAS/Port2004/GM/GM-518.htm>. Acesso em: mar. 2013.

Calandino, D.; Wehrmann, M.; Koblitz, R. Contribuição dos assentamentos rurais no desmatamento da Amazônia: um olhar sobre o Estado do Pará. Desenvolvimento e Meio Ambiente, 26, 161-170, 2012.

Carneiro, F.F.; Tambellini, A.T.; Silva, J. A.; Haddad, J. P. A.; Búrigo, A. C.; Sá, W. R.; Viana, F. C.; Bertolini, V. A. Saúde de famílias do Movimento de Trabalhadores Sem Terra e dos boias-frias, Brasil. Revista de Saúde Pública, 42(4), 757-763, 2008.

Coca, E. L. de F. Debatendo o conceito de Reforma Agrária: considerações sobre os tipos de assentamentos rurais no Brasil. Campo-Território: Revista de Geografia Agrária, 8(16), 170-197, 2013.

Denich, M.; Vlek, P. L. G.; Sá, T. D. de A.; Vielhauer, K.; Lücke, W. A Concept for the Development of Fire-free Fallow Management in the Eastern Amazon, in Brazil. Agriculture Ecosystems \& Environment, 110, 43-58, 2005.

Fernandes, L. A.; Cotrim, M.; Fleck, L. F.; Melgarejo, L.; Oliveira, A. Indicadores de Desenvolvimento Sustentável para Assentamentos de Reforma Agrária. In: Anais do VII Encontro da Sociedade Brasileira de Economia Ecológica. Fortaleza, 28 a 30 de nov. 2007.

Ferrante, V. L. S. B.; Barone, L. A. Assentamentos rurais e poder local: os rumos da descentralização da reforma agrária. In: Bergamasco, S. M. P. P. et al. Dinâmicas familiar, produtiva e cultural nos assentamentos rurais de São Paulo. Araraquara: UNIARA; Campinas: FEAGRI/UNICAMP, São Paulo: INCRA, 2003. p. 157-185.

Ferrari, E. Um novo olhar sobre a diversidade das estratégias organizativas locais. Organizações locais na promoção do desenvolvimento. Revista Agriculturas, 4(2), 4-6, 2007.

Gazzinelli, M. F.; Lopes, A.; Pereira, W.; Gazzinelli, A. Educação e participação dos atores sociais no desenvolvimento de modelo de gestão do lixo em zona rural em Minas Gerais. Revista Educação \& Sociedade, 22(74), 225-241, 2001.
Giatti, L. L.; Cutolo, S. A. Acesso à água para consumo humano e aspectos de saúde pública na Amazônia Legal. Ambiente \& Sociedade, 15(1), 93-109, 2012.

Girardi, E. P.; Fernandes, B. M. A. A luta pela terra e a política de assentamentos rurais no Brasil: a reforma agrária conservadora. Agrária, 8, 73-98, 2008.

Guerra, R. M. N. É possível atingir a sustentabilidade nos assentamentos de Reforma Agrária na Amazônia Legal? O caso do PDS São Salvador no Estado do Acre. Brasília, Dissertação (Mestrado em Desenvolvimento Sustentável) - Universidade de Brasília - Centro de Desenvolvimento Sustentável, 2002.

INCRA - Instituto Nacional de Colonização e Reforma Agrária. Pesquisa de Avaliação da Qualidade dos Assentamentos de Reforma Agrária. Belém, 2010. p. 15 (Documento digital).

INCRA - Instituto Nacional de Colonização e Reforma Agrária. Relação dos Projetos da Reforma Agrária. Período da Criação do Projeto: 01/01/1900 até 18/08/2011. Disponível em: <http://www.incra.gov.br/index.php/ reforma-agraria-2/projetos-e-programas-do-incra/relacao-de-projetos-de-reforma-agraria>. Acesso em: abr. 2013.

IPAM - Instituto de Pesquisa Ambiental da Amazônia. Desmatamento nos assentamentos da Amazônia: histórico, tendências e oportunidades. Brasília: IPAM, 2016.

Kronemberger, D. M. P.; Carvalho, C. N. de; Clevelário Júnior, J. Indicadores de sustentabilidade em pequenas bacias hidrográficas: uma aplicação do "Barômetro da Sustentabilidade" à Bacia do Jurumirim (Angra dos Reis, RJ). Revista Geochimica Brasiliensis, 18(2), 86-92, 2004.

Kronemberger, D. M. P.; Clevelário Junior, J.; Nascimento, J. A. S do; Collares, J. E. R.; Silva, L. C. D. da.Desenvolvimento sustentável no Brasil: uma análise a partir da aplicação do "barômetro de sustentabilidade". Sociedade e Natureza, 20(1), 25-50, 2008.

Le Tourneau, F.M.; Bursztyn, M. Assentamentos rurais na Amazônia: contradições entre a política agrária e a política ambiental. Ambiente \& Sociedade, 8(1), 111-130, 2010.

Lepri, M. P. Projetos de assentamento ambientalmente diferenciados: a reforma agrária eco-socialistado séc.XXI. In: Anais da II Conferência do Desenvolvimento - IPEA. Brasília, nov. 2011. 
Marchand, G.; Le Tourneau, M. O desafio de medir a sustentabilidade na Amazônia: os principais indicadores mundiais e a sua aplicabilidade ao contexto amazônico. In: Vieira, I. C. G.; Toledo, P. M. de; Araújo, R. (Orgs.) Ambiente e Sociedade na Amazônia: uma abordagem interdisciplinar. Rio de Janeiro: Garamond, 2014. p. 195-220.

MDS - Ministério do Desenvolvimento Social e Combate à Fome. Relatório de Informações Sociais. Disponível em: http://aplicacoes.mds.gov.br/sagi/RIv3/geral/relatorio. php\#Visão Geral>. Acesso em: mar. 2013.

Ministério Público do Pará. Sistema de informação de indicadores sociais - SIIS. Disponível em: <https://www2. mppa.mp.br/sistemas/gcsubsites/index.php?action=Orgao. site\&oOrgao $=53>$. Acesso em: mar. 2013.

Moraes, J. A.; Monteiro, M. S. L. Agrotóxicos e meio ambiente: do uso aos agravos à saúde do trabalhador rural. In: III Encontro da ANPPAS. Brasília, 23 de maio 2006. Disponível em: <Www.anppas.org.br/encontro_anual/ encontro3/arquivos/TA104-15032006-150215.DOC.>. Acesso em: out. 2013.

Motta, S. Saneamento. In: Rouquayrol, M. Z. Epidemiologia e saúde. 4. ed. Rio de Janeiro: Medsi, 1994. p. 343-364.

Noda, S. N. Utilização e apropriação das terras por agricultura familiar amazonense de várzeas. In: Diegues, A. C.; Moreira, A. C. (Orgs.). Espaços e recursos naturais de uso comum. São Paulo: NUPAUB/USP, 2001. p. 181-203.

Pereira, C. A.; Vieira, I. C. G. A importância das florestas secundárias e os impactos de sua substituição por plantios mecanizados de grãos na Amazônia. Interciência, 26(8), 337-341, 2001.
Prescott-Allen, R. Assessing progress toward sustainability system assessment method illustrated by wellbeing of nations. Cambridge: IUCN, 1999.

Silva, M. A. D. Assentamento e sustentabilidade. Sociedade e Cultura, 4(1), 85-103, 2001.

Silva, E. P. Reforma agrária e desenvolvimento rural sustentável, sob a abordagem do Cooperativismo e da Agroecologia: o caso dos assentamentos do Nordeste Paraense. Amazonas (Trabalho de Conclusão de Curso) UNAMA, 2011.

Sparovek, G. A qualidade dos assentamentos da reforma agrária brasileira. São Paulo: Páginas e Letras, 2003.

Torres, E. F. O papel dos atores sociais na consolidação dos assentamentos. In: XI Congresso Brasileiro de Sociologia, Campinas, 1 a 5 de set. 2003.

Veiga, J. E. da. Desenvolvimento Sustentável: o desafio do século XXI. Rio de Janeiro: Garamond, 2010.

Vieira, I. C.G. et al. Bases técnicas e referenciais para o programa de restauração florestal do Pará: um bilhão de árvores para a Amazônia. Belém: IDESP, 2009. 109 p.

Vieira, I. C. G.; Araujo, R.; Toledo, P. M. de. Dinâmicas produtivas, transformações no uso da terra e sustentabilidade na Amazônia. In: Silfert, N.; Cardoso, M.; Magalhães, W.; Lastres, H. (Orgs.). Um olhar territorial para o desenvolvimento da Amazônia. 1. ed. Rio de Janeiro: BNDES, 2014. p. 370-395.

WFTO - World Fair Trade Organization. Ten principles of fair trade, 2004. Disponível em: <http://wfto.com/fair-trade/10-principles-fair-trade>. Acesso em: abr. 2014. 